\title{
Aspects of Municipal Solid Waste Management in Allahabad City: A Questioner Survey of the Citizens
}

\author{
Vijai Krishna ${ }^{1} \&$ Sadhana Chaurasia ${ }^{2}$ \\ ${ }^{1}$ Research Scholar, Mahatma Gandhi Chitrakoot Gramodya University, Chitrakoot, Satna, M.P. \\ ${ }^{2}$ Associate Professor, Mahatma Gandhi Chitrakoot Gramodya University, Chitrakoot, Satna, M.P.
}

\begin{abstract}
As the economic development takes place in a country the generation of the municipal solid waste also increases. Not only this but the characteristics of the municipal solid waste also changes.This research has been conducted for the evaluation of the status of the municipal solid waste of the Allahabad city. A questioner has been prepared to find out the general perception of the citizen of the city of Allahabad about the different aspects of the municipal solid waste and its consequences and management in the city. Questioner contains questions related to the types, sources, methods of collection, storage, transportation etc. of the municipal waste generated in the city of Allahabad. At the end of this questionnaire suggestion also has been requested from the citizens for the better management of solid waste.
\end{abstract}

Key words: Municipal solid waste, questioners, waste collection, secondary storage, dustbins, citizen audit.

\section{Introduction}

A positive correlation can be seen in between population explosion, industrialization, modern life style, economic boom and increase in the quantity and volume of the municipal solid waste worldwide. The per capita generation of MSW has also increased tremendously with improved life style and social status of the populations in urban centres.(Sharholy et al. 2007). As more land is needed for the ultimate disposal of these solid wastes, issues related to disposal have become highly challenging task.(Idris et al. 2004). According to Mizpah et al. (2009) integrated waste management is an accepted approach for management of solid waste in developed and developing nations both. Shekdar et al. (1991) investigated that population of urban areas of India is increasing very fast as a result of industrial growth in urban areas due to which municipalities are facing problems to provide basic civic facilities to people including waste management. Seadon (2006) clarified that solid waste management is at least four millennia old issue, which forces us to think about the integrated solid waste management. Read (1999) formulated that policies regarding waste management are being important social and political concerns throughout the world. Rhyner (1992) claimed that the design of a solid waste management system depends on waste quantities predictions with long and short term variations occur in it. According to Ciuta (2015) analysis of generation rates and composition of solid waste helps in improvement of the waste management system and recycling of waste. Metin et al. (2003) concluded that proper management of solid waste needs suitable data on a long term basis with higher frequencies and reliable statistics. The data regarding present situation of municipal solid waste management can be obtained efficiently from the citizens of a city, as the citizens of a city are directly affected by the impacts of the mismanagement of the solid waste; so, in this study the data has been collected regarding the municipal solid waste management by the use of a questioner. There are 80 wards in the city of Allahabad, so about 10 questioners have been distributed in every ward. One thousands questioners were selected for the final assessment. Data obtained from these questioners were arranged and results were presented in the form of graphs. These graphs and data were analyzed with suitable logics and facts.

\section{Material And Method}

Study area--The geographical extension of Allahabad city falls from $25^{\circ} 27^{\prime} \mathrm{N}$ to $25.45^{\circ} \mathrm{N}$ and $81^{\circ} 51^{\prime}$ $\mathrm{E}$ to $81.85^{\circ} \mathrm{E}$. The geographical area of the city is about 62 square $\mathrm{km}$. Census data of 2011 states Allahabad city as the $32^{\text {nd }}$ most populous city in India. The population of the city is 975000 . The city has poor sex ratio at 807 females per 1000 males. The male and female population of the city are 539,772 and 435,621. About 10\% population falls between $0-6$ years. The literacy rate of the city was $81 \%$ which is better than many other cities of U.P. the population growth rate of the city is $23 \%$. According to 2001 census the average population density is 16,559 persons per sq k. m. there are 185 slums in the city.About $30 \%$ population of the city lives in the slums which can be categorised as urban poor category.

A questioner has been prepared to find out the general perception of the common citizen of the city of Allahabad about the different aspects of the municipal solid waste and its consequences and management in the city. Questioner contains questions related to the types, sources, methods of collection, storage, transportation etc. of the municipal waste generated in the city of Allahabad. Questioner has been provided to about one 
thousands citizens and some time has been given to fill the answers. Time has been given so that family members can discuss on different issues and correct answer can be obtained. Questioner has been provided to different types of working people like household, shops, government offices, private offices etc. houses of every types has been selected including from very poor to very rich households, every ward etc. shops of every types has been selected including cloth, stationary, food items, electronics and electrics, general stores, medical stores, hardware items, vehicle showrooms, malls etc. there are 80 wards in the city of Allahabad, so about 10 questioners have been distributed in every ward. Numbers of questioners were also depended on the area and population of the ward. More questioners were distributed in the wards with larger area or larger population.

After a certain time (about one week) questioners were collected and numbered so that they can be easily arranged. Few citizens were not interested in filling the questioner, so these types of questioners were discarded out and not assessed for the final conclusion. One thousands questioners were selected for the final assessment. Data obtained from these questioners were arranged and results were presented in the form of graphs. These graphs and data were analyzed with suitable logics and facts.

\section{Results And Discussion}

1. Dustbin in Mohalla--It has been seen that $52 \%$ of the citizens under survey accepted that there are dustbins present in their respective mohalls while only $48 \%$ answered that there are no dustbins in their respective mohalls. It shows that about half of the city has the dustbins and other half is lacking the presence of dustbins. So this is also an important reason for the inefficient collection of the municipal solid waste and so a big amount of the solid waste being thrown on the road sides which further becomes the breeding place of agents of infectious diseases and a place for the search of food material for the castles, dogs and pigs etc.

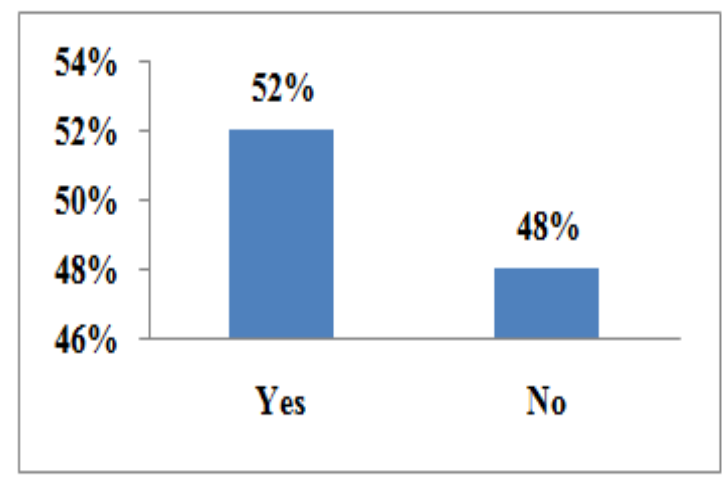

Fig 1: $\%$ of mohallas with dustbins

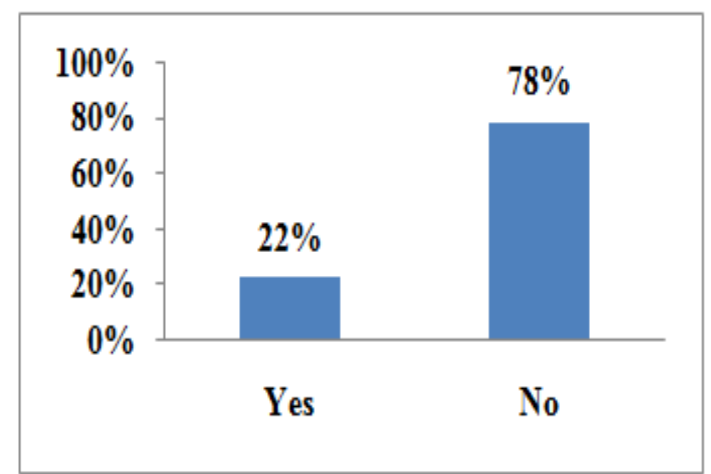

Fig 2: \% of mohallas with secondary storage

2. Secondary storage in Mohalla--Only $22 \%$ of the citizens were agreeing that secondary waste storage depot is situated in nearby areas of their respective mohalls rest $78 \%$ were not agreeing with this. According to Municipal Corporation the reason for the less secondary storage depot is that now most of the waste is being collected by the waste collection agencies so there is no requirement of this secondary storage depot. Due to less secondary waste storage depot a large amount of the municipal waste is being dumped and thrown on the road sides near to the dustbins which again creates unaesthetic environment and becomes the breeding place of agents of infectious diseases and a place for the search for the food by cattle, dogs and pigs. Some time it also resists the smooth traffic on the road.

3. Waste collection system-- About $36 \%$ of the citizens accepted that method of waste collection in their respective residential area is door to door waste collection. In this method the person responsible for the waste collection comes on the door and whistles so that people in the home get informed that waste collector has came and then they give the waste of their home to him. The waste collector comes with a trolley in which he collects the waste and goes to next door. About $64 \%$ of the citizens accepted that the waste collection system was not of door to door but of community bins type, in this system they have to throw the waste of their homes time to time in large community bins which are kept on the road turnings or road crossing or road sides. In case of community bin collection system when the bins get filled people starts to throw the waste in the sides of the bins which again become non aesthetic for the city and becomes the breeding place of the agents of the infectious diseases and a site for the search of food for the cattle, dog and pigs. Due to lack of door to door collection method many times people do not go to the community bins but throw their waste on the roads 


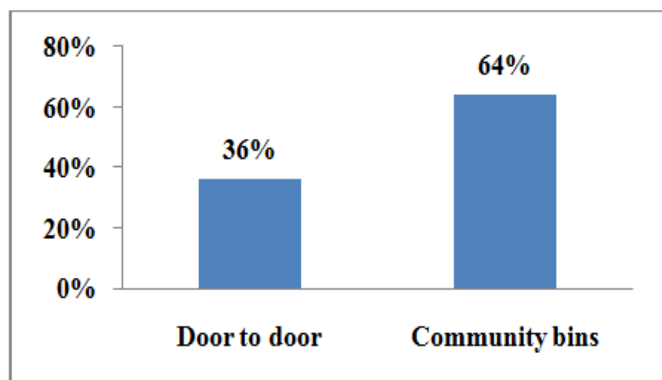

Fig 3: \% of types of Waste collection system

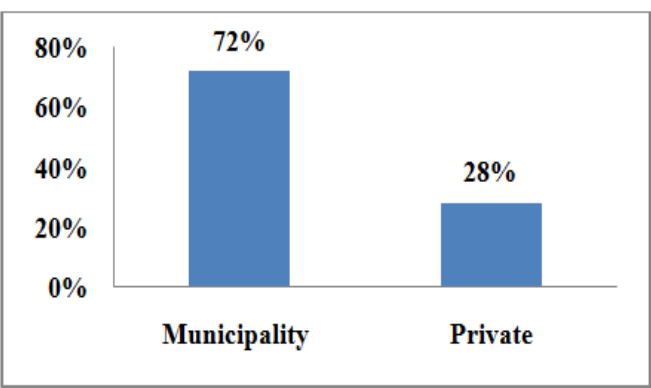

Fig 4: $\%$ of waste collection agency

4. Waste collection agency--In Allahabad waste is being collected by the Municipality and private agency both. The private agency is the Allahabad Waste Processing Private Limited (AWP). The survey revealed that $72 \%$ of the citizens are agreeing that the waste is being collected mostly by the Municipality while $28 \%$ are agreeing that waste collection agency is AWP. It has been seen that AWP is more efficient in waste collection but the work area of AWP is very limited.

5. Type of waste--During survey it has been found that most the citizens (97\%) were agreeing that the daily waste produced from their homes contains food or flower and plastic while $83 \%$ citizens were agreeing that the daily waste contains paper/cardboard and about $91 \%$ were agreeing that the daily waste contains plastic.

6. Satisfaction with waste collection--About $32 \%$ citizens answered that they are satisfied with the degree of waste collection while $68 \%$ were not satisfied. This higher level of dissatisfaction shows that in most part of the city the waste collection service is not efficient. The reason behind this is that the waste collection is being carried out by the municipality but with fewer resources like less human resources and inefficient vehicles and regularity is also a problem.

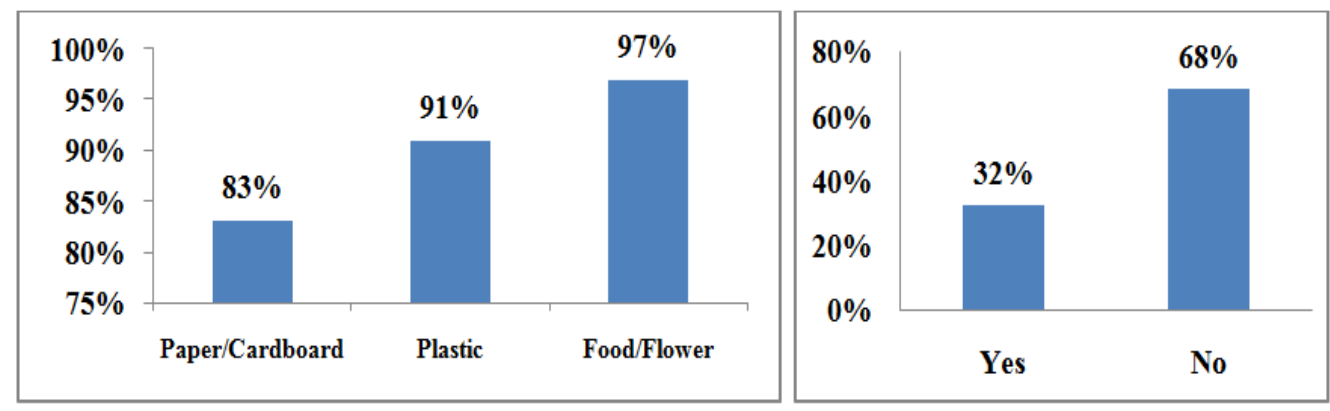

Fig 5: $\%$ of type of waste

Fig 6: \% of satisfaction with waste collection

7. Waste collection Frequency--About 52\% respondents were replied that waste is collected daily, $34 \%$ replied for 2-3 days, $10 \%$ replied for $4-5$ days and $4 \%$ replied for weakly collection of municipal solid waste.

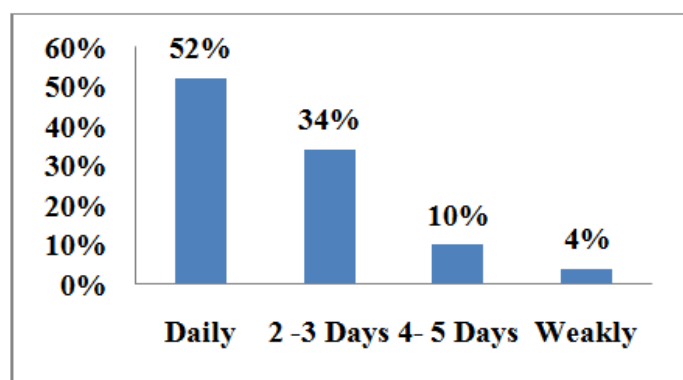

Fig 7: \% of waste collection frequency

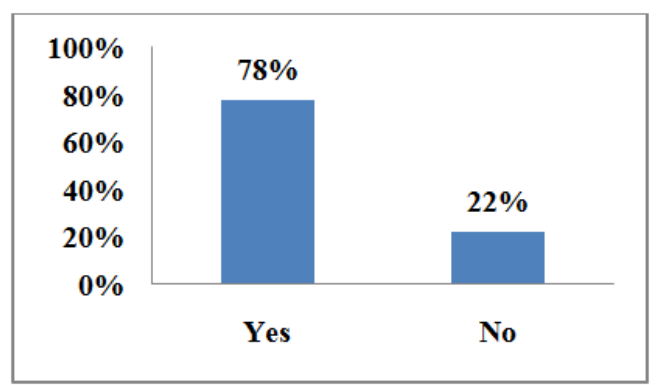

Fig 8: \% of will to pay for waste collection

8. Will to pay for waste collection--About $78 \%$ of the citizens answered that they are ready to pay for the waste collection service but $22 \%$ denied this. The people denied argued that no matter how much they pay but government services and especially municipal services can never be in proper way. So if the people are not ready to pay for the waste collection service then this is a problem of lack of confidence in municipal administration and not a problem of inability to pay. 
9.Sell waste to kabadiwala--Most of the people (92\%) accepted that they sell their solid waste from home to the local scrappers or kabadiwala while a very little $(8 \%)$ denied this. The reason behind this is that no one wants to have solid waste in their home and also it is very easy to sell this waste to local scrappers. This practice also provides them money from waste which was otherwise worthless.

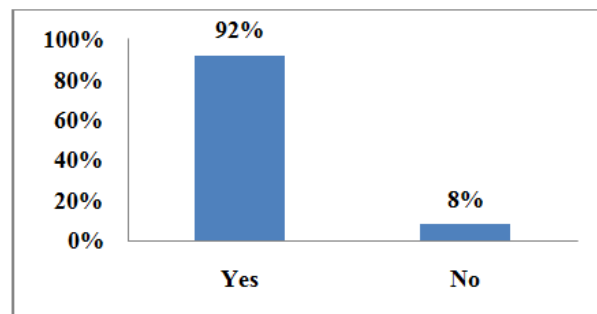

Fig 9: \% of Sell waste to kabadiwala

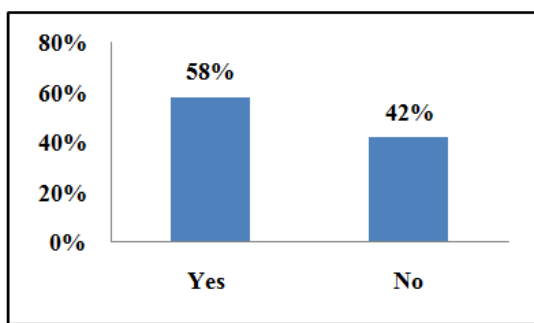

Fig 10: $\%$ of throwing flower to rivers

10.Throwing flower to rivers--58\% citizens accepted that they and their family members throw the flowers and other materials of worship into the river while $42 \%$ denied that. The reason of throwing the flowers etc. into the river is that the people believe in the holiness and purifying capacity of the river Ganga and Yamuna. The result of this is that these organic content increases the Biochemical Oxygen Demand (BOD) level of the river water.

11. Have dustbin at home--Most of the citizens $56 \%$ have answered that they have dustbin at their home while $44 \%$ denied. The reality is that most of the houses have dustbin of different shapes and sizes. People use it to collect the solid waste of their houses daily and then put these waste on the road sides or road crossings or community bins or give it to door to door waste collectors. It is a good habit of people to have dustbins in their home and it is an old practice too. The disadvantage of this practice is that these dustbins produce the mixed solid waste due to which it is very difficult to process it.

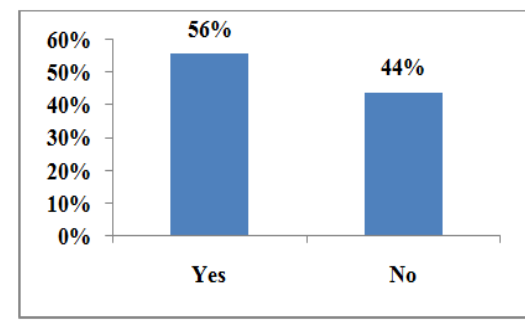

Fig 11: \% of people having dustbin at home

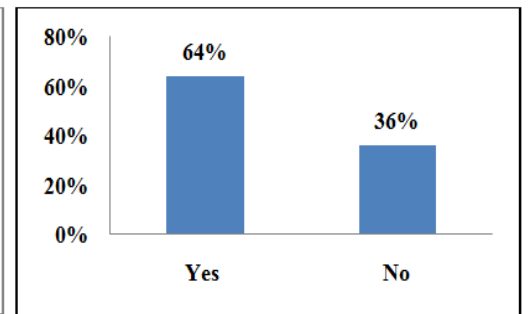

Fig 12: \% of daily sweeping on lanes

12.Daily sweeping on lane--About $64 \%$ of citizens answered positively that daily sweeping take place at their lanes and roads but $36 \%$ denied that. Not only this but it also seen that the areas where daily sweeping take place the sweeping is not proper. The reason for the non sweeping in certain areas is that there is great lack of sweeper and their supervision is also not very good. Their wages are also not good so some time they go to do some other work too.

13.Waste increases during festivals--Most of the citizens $(93 \%)$ were agreeing that the amount of the solid waste is being increase during festival season. The reason behind this is that in Indian scenarios during festival the cleanliness of the house takes place in the result of which large amount of the solid waste produces not only this but during festivals a lot of purchasing also take place due to which also the amount of solid waste increase.

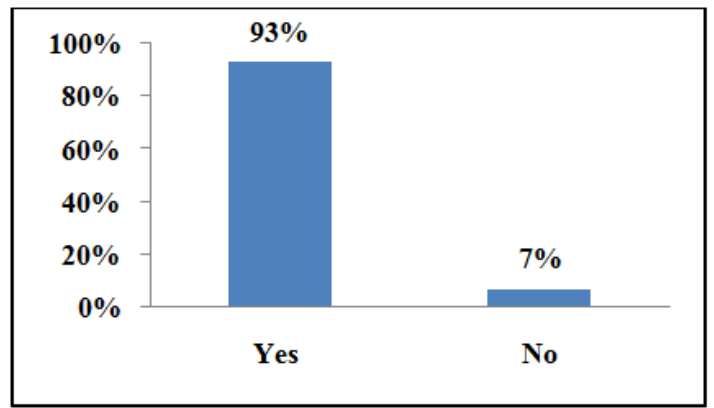

Fig 13: $\%$ of waste increases during festivals 


\section{Important suggestions obtained from the citizens through the survey-}

14.1. There should be daily waste collection--Most of the people are of the view that there should be daily collection of the waste so that the amount of the solid waste may be under control and do not increase very much. If the amount of the solid waste is less in a day then it is very easy to handle it like collecting and processing otherwise municipality or private agencies have to spend their money and resources to handle it.

14.2. Large bin size and durable bins--It has been seen that most of the time most of the dustbins are overflowing; the reason behind this is that the size of the dustbins are not large. In Allahabad there are two types of the dustbin are placed one is community pacer (800) and another one is dumper placer (100) the capacity of which are 1100 liters and 8000 liters respectively. So maximum area is covered by the community placers but their capacity is not enough. So this is the demand of time to increase the capacity of the community placers.

14.3. More bins on the road sides--The number of the community bins or community placers is not enough so they are placed at large distance with each other. So people have to walk a long distance to put their waste into the bin due to which they avoid it and throw the waste here and there. So the number of community placers should be increase.

14.4. Protection of bins from the animals and steeling--It is also a great problem that some persons steel the bins to resell it as scrap. The bin should be tied or be so heavy that no one can move it. The animals also disturb the bins as they try to search the bins for the food and in that case they fell the bins on the roads, so bin should be like this that they cannot be affected by the animals.

14.5. Separation of waste should be carried out-- This is a major concern for the waste handling that the waste should be separated at source. Although most of the people are saying for the separation of waste but the problem is that they do not know the separate categories of the solid waste but the big problem is that they are not actually interested to do so because they think that it will take a lot of time and they will need different bins and more place to keep these extra bins. So they generally keep all the waste in the same bin and produce the mixed solid waste.

14.6. Waste to energy method should be utilized--Few persons are aware that the waste can be used to produce energy so they suggested that the waste should be used to produce the energy even they do not know the basic concept of this. People concerned that there is a huge amount of the waste is being produce in the city so it should be use for reuse, recycle and energy production.

14.7. Better sewage management--Sewage sludge is also a municipal solid waste, so the people are concerned that this sludge should also be disposed or managed because sludge remains in the drain due to which the drains starts to overflow. The problem is that just before the monsoon season municipality dug out the sludge from the drains and from the sewage treatment plants and keeps it on the road sides which during the rain get again reaches to the drains and choked the drains.

14.8. No burning of waste should be take place--Many times the waste collected in dustbins are burned by the waste collectors so that they have to handle less amount of the waste but this practice produce smog and particulate matter and poisonous gases which may harm the people as well as it is also a fire hazard. Not only this but the waste which can be easily recycle or reuse also be destroyed, so the people suggests that the burning of the waste in bins should not be practice.

14.9. Closed waste collection vehicles--Waste collection trucks are generally open types so when they carry the waste from one place to another a fraction of the waste get scattered on the road sides which creates a anaesthetic condition. So the waste collection vehicles should be closed type.

14.10. Citizen audit of sanitation condition--The sanitation condition should be audited by the civil society too. This civil society should inspect all aspects of the sanitation including solid waste handling and should give important suggestion to the government and municipality.

14.11. Involvement of social media like facebook etc. to obtain real time status of waste management--The new information technologies can also be utilized for updating the real time status of the solid waste like social media e.g. facebook, what's up, SMS, MMS, images, $3 \mathrm{G}$ mobile network etc. the advantages of this is that this is very fast and easy to access by any one. 


\section{Conclusion}

About 52\% respondents agreed that there were dustbins in their mohallas. Only $22 \%$ respondents replied that there is secondary storage depot in their mohallas. Only 36\% respondents approved that there is door to door collection system exist in their mohallas and 64\% respondents answered that there is only community bin collection system exist in their mohallas. The survey revealed that $72 \%$ of the citizens are agreeing that the waste is being collected mostly by the Municipality while $28 \%$ are agreeing that waste collection agency is Allahabad Waste Processing Private Limited (AWP). It has been found that all the citizens were agreeing that the waste produced from their homes contains food or flower and plastic while $80 \%$ citizens were agreeing that the waste contains paper/cardboard and about $90 \%$ were agreeing that the waste contains plastic. About $32 \%$ citizens answered that they are satisfied with the degree of waste collection while $68 \%$ were not satisfied. About $78 \%$ of the citizens answered that they are ready to pay for the waste collection service but $22 \%$ denied this. Most of the people accepted that they sell their solid waste from home to the local scrappers or kabadiwala while a very little part $(8 \%)$ denied this. $58 \%$ citizens accepted that they and their family members throw the flowers and other materials of worship into the river while $42 \%$ denied that. Most of the citizens $56 \%$ have answered that they have dustbin at their home while $44 \%$ denied. About $64 \%$ of citizens answered positively that daily sweeping take place at their lanes and roads but 36\% denied that. Most of the citizens $(93 \%)$ were agreeing that the amount of the solid waste is being increase during festival season. Important suggestions obtained from the citizens through the survey were that there should be daily waste collection, large bin size and durable bins, more bins on the road sides, protection of bins from the animals and steeling, separation of waste should be carried out, waste to energy method should be utilized, better sewage management, no burning of waste should be take place, closed waste collection vehicles, involvement of social media like facebook etc. to obtain real time status of waste management, citizen audit of sanitation condition.

\section{References}

[1]. Ciuta Simona et al., Urban and Rural MSW Stream Characterization for Separate Collection Improvement, Sustainability, 7, 2015, 916-931.

[2]. Idris A., Inane B. and Hassan M. N., Overview of waste disposal and landfills/dumps in Asian countries, Material cycles and waste management, 16, 2004, 104-110.

[3]. Metin E. et al., Solid waste management practices and review of recovery and recycling operations in Turkey, Waste Management, $23,2003,425-432$.

[4]. Mizpah Asase et al., Comparison of municipal solid waste management systems in Canada and Ghana: A case study of the cities of London, Ontario, and Kumasi, Ghana. Waste Management, 29, 2009, 2779-2786.

[5]. Read Adam D., Making waste work: making UK national solid waste strategy work at the local scale, Resources, Conservation and Recycling, 26, 1999, 259-285.

[6]. Rhyner Charles R., Monthly variations in solid waste generation. Waste Management \& Research, 10, 1992, 67-71.

[7]. Seadon J. K., Integrated waste management - Looking beyond the solid waste horizon. Waste Management, 26, $2006,327-1336$.

[8]. Sharholy M., Ahmad K., Vaishya R. and Gupta R., Municipal solid waste characteristics and management in Allahabad, India. Waste management, 27 (4), 2007, 490-496.

[9]. Shekdar A. V., Krishnaswamy K. N., Tikekart V. G. and Bhide A. D., Long-term planning for solid waste management in India, Waste management \& research, 9, 1991, 511-523. 